\title{
Community-based programs to tackle environmental education and COVID-19: A case study from Millburn, New Jersey
}

\author{
Radhika Iyengar ${ }^{1} \cdot$ Haein Shin $^{1}$
}

Published online: 29 May 2020

(C) UNESCO IBE 2020

\begin{abstract}
Contextual and social realities must be built into any educational program for activism to take place. This case study examines an education and environment program which has adapted to the social distancing measures of COVID-19, resulting in an even more community-reliant and community-driven program than the program designers initially intended. The Eco Ambassador Program uses environmental activism within a space that supports mental health during COVID-19 social isolation. While community engagement and action have been elements of the program, the program has transformed to utilize new levels of social capital in the program's network, to overcome the obstacles presented in regular programming. Many aspects of the critical pedagogy of space are utilized to conceptualize this educational program during the pandemic. The limitations of in-person interactions in defined learning spaces led to more technology-reliant programming, hence broadening the space of place-based learning, while enabling personal spaces and personal environments to become new learning spaces.
\end{abstract}

Keywords Community · Environment · Education · Coronavirus · COVID-19 · Case study $\cdot$ Place-based education $\cdot$ Community-based learning

COVID-19 social isolation brought unprecedented challenges for the educational opportunities for students across the world. As of April 17, 2020, 1,575,270,054 learners were affected according to UNESCO statistics, with $91.3 \%$ of total enrolled learners staying at home due to 191 country-wide school closures (UNESCO 2020). When the closures were announced in March 2020, many schools did not have time to assemble online resources

Radhika Iyengar

iyengar@ei.columbia.edu

Haein Shin

hshin@ei.columbia.edu

1 Center for Sustainable Development, Earth Institute, Columbia University, 475 Riverside Drive, Room 401, Mail Code: 3277, New York, NY 10115, USA 
and structure learning plans according to students' learning levels. During the pandemic, however, students found themselves indefinitely at home for all hours of the day, which gave them an opportunity to learn from their immediate environments. Which trees bloom in March and April? Which produce is in season? Can some of the seeds from home kitchens be planted and regrown? What seasonal patterns, animals, and plants are specific to my hometown? Learning from their immediate environment became key to connect students with a sense of space, community, and that community's people. It became even more urgent to learn about the pandemic, and also to keep healthy mentally and socially, by getting and staying connected.

This article uses the critical pedagogy of place to explore and learn from the exchanges among community members in Millburn, New Jersey. Specifically, it examines the Eco Ambassador Program, an initiative developed at the Center for Sustainable Development in Columbia University's Earth Institute that helps facilitate this technology-aided learning interaction. The article explores one research question: how can a place's cultural and social capital be used to provide a learning platform for the community, especially during the COVID-19 pandemic? It intends to highlight the role of social networks that can facilitate action on environmental issues, taking place in a specific community and formed primarily around a shared ethnic background.

The study first explains the theoretical framework used for the analysis. It explains the contexts, inputs, processes, and outcomes. Following the framework, the next section reviews the pedagogical lens that the educational program uses. This literature review explains the critical pedagogy of place and its main tenets. The second important element to understand the underlying mechanisms of the educational approach adopted, namely the cultural capital of the community and the role it plays in education. This section is followed by a discussion of the educational program itself, explaining the Eco Ambassador Program, its genesis, and the role it has played during the COVID-19 pandemic. The chapter concludes by summarizing the factors that may blur the lines between community and schools on environmental issues.

The study is situated in Millburn, New Jersey, a town located in northern New Jersey at the foothills of the South Mountain Reservation. The population in 2018 was 20,171, with $32 \%$ under the age of 18 . It is predominantly white-dominant, with $70 \%$ of the population belonging to this category. The Asian population is around $22.2 \%$, primarily South East Asian. The median household income was $\$ 214,110$ as of 2018, with around 6,577 households (United States Census Bureau 2018).

\section{Theoretical framework}

The theoretical framework for this article is illustrated in Figure 1. The context on which the theoretical framework is set includes the immediate surroundings where the residents were able to see environmental degradation around them, especially highlighting issues related to plastic waste and single-use plastics' use and disposal. The residents therefore had already shown interest in some environmental and climate-related action. Some events were circumstantial, such as the coronavirus (COVID-19) outbreak, which influenced the educational pattern of the community. The inputs were in the form of informal networks that were already established, such as the social groups residents formed on WhatsApp and Facebook for raising environmental awareness. Meanwhile, community-based local organizations such as the Millburn Green Schools Committee team had been consistently 


\begin{tabular}{|c|c|c|c|}
\hline Contexts & Inputs & Processes & Outcomes \\
\hline $\begin{array}{l}\text { Surroundings } \\
\text { Environmental } \\
\text { degradation in the } \\
\text { surroundings. } \\
\text { - Plastic waste } \\
\text { accumulation in the } \\
\text { town. } \\
\text { Situational } \\
\text { COVID-19 arrival. } \\
\text { People } \\
\text { - Interest from the } \\
\text { parents and children. }\end{array}$ & 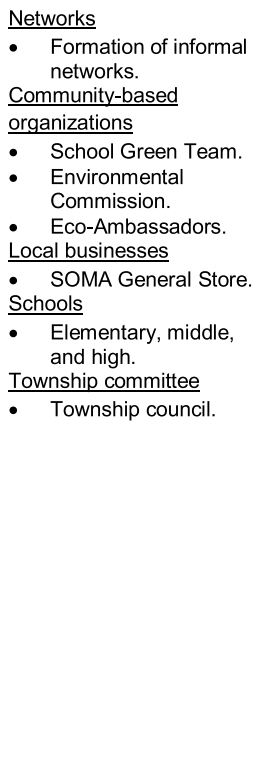 & $\begin{array}{l}\text { Networks } \\
\text { - } \quad \begin{array}{l}\text { Educating residents on } \\
\text { single-use plastic. }\end{array} \\
\text { Organizing composting } \\
\text { sessions. } \\
\text { - Organizing food waste } \\
\text { sessions. } \\
\text { Organizing a utensil } \\
\text { bank in the community. } \\
\text { Community-based } \\
\text { organizations } \\
\text { School Green Team } \\
\text { action with the schools } \\
\text { on recycling education. } \\
\text { - Make residents aware } \\
\text { of COVID-19 } \\
\text { precautions. } \\
\text { Environmental } \\
\text { Commission helping to } \\
\text { ban single-use plastic. } \\
\text { Eco-Ambassadors } \\
\text { conducting small } \\
\text { research projects. } \\
\text { Local businesses } \\
\text { SOMA General Store. } \\
\text { Schools } \\
\text { Eco-club at elementary } \\
\text { schools. } \\
\text { Township committee } \\
\text { Township council. }\end{array}$ & $\begin{array}{l}\text { Networks } \\
\text { - } \quad \begin{array}{l}\text { Made residents aware } \\
\text { of composting. } \\
\text { Made residents aware } \\
\text { of food waste. } \\
\text { Made residents aware } \\
\text { of plastic waste. } \\
\text { Made residents aware } \\
\text { of the pandemic. } \\
\text { Community-based } \\
\text { organizations } \\
\text { Increased knowledge } \\
\text { among students on } \\
\text { reducing school waste. } \\
\text { Improved practices of } \\
\text { school on reducing } \\
\text { waste. } \\
\text { Single-use plastic } \\
\text { banned in the town. } \\
\text { Improved knowledge } \\
\text { on the part of the Eco } \\
\text { Ambassadors. } \\
\text { Local businesses } \\
\text { Increased eco-friendly } \\
\text { merchandise in the } \\
\text { community. }\end{array}\end{array}$ \\
\hline
\end{tabular}

Figure 1 Theoretical framework

working with the schools on environmental issues. Regular Eco Ambassadors Program attendees met several times over the course of the year, starting in 2019, at conferences, workshops, and community events.

As a result of these inputs, the social networks helped to organize many grassroots events in Millburn. For example, the Millburn Climate Strike was organized by a community member, Vanita Gangwal, and a few others. Some other community members collectively created a utensil rental system open for anyone in town to use, with the aim of eliminating the need to purchase disposable, single-use utensils for social gatherings and events. The more formally organized groups, such as the Schools Green Team, helped to promote awareness and offered information that would orient the schools to become zero-waste, or at least to minimize waste and usage of single-use plastics. Priya Patel and Lillian Cho are the co-chairs of the Millburn Green Schools Committee. Priya is also a member of the Climate Action Group. The Millburn Environmental Commission helped to formulate a draft bill, which was later approved by Millburn Township, to ban single-use plastics in town.

The outcome of these activities increased residents' awareness and knowledge, enabling them to take actionable steps that were pro-environment. This included having fewer parties where single-use plasticware was used. Some of the events organized by the various community groups attempted to restrict the use of plastic in general. The Eco Ambassadors had completed individual research projects and had become active voices in the community on local environmental challenges. Their knowledge did not stay at the desk research stage-several Eco Ambassadors took the initiative to speak with local businesses, school leaders, and peers about potential solutions, and they continued to converse and share 
eco-friendly messages via posters, flyers, and personal conversations. There was also an upsurge of eco-friendly merchandise among many local vendors.

By the time of the COVID-19 lockdown, these active and engaged community networks were already formed with an awareness of and passion for environmental issues affecting the community at large. When the COVID-19 lockdown started, many residents were connecting with each other to discuss the virus in relation to the climate debate. Therefore, at the time of the pandemic, the Eco Ambassadors Program was able to expand all of its existing programs and go online. There was already a base community with people who were already engaged with the program, who could use the new online platform to share their knowledge and research on environmental issues.

\section{Literature review}

Two theoretical perspectives best explain the theoretical underpinning for this case study: the critical pedagogy of place and the cultural capital of the community. The notion of place is important since this educational approach is community-based. As a result of social distancing practiced by the entire community by staying, working, and learning at home, this education practice tapped into a new space-bound format. This raises several questions. What makes up a community? What is a newly defined boundary that forms a neighborhood? How are neighborhoods and relationships cultivated with limited in-person interactions? How can any space become a new learning space?

Second, education needs to be relevant and contextual. How is education informed? How does information and knowledge reflect, relate and apply to the cultural capital of a setting? What informs the community in Millburn? Which contextual realities need to be taken into consideration to make education relevant and impactful?

\section{Critical pedagogy of place}

Ruitenberg (2005) pointed out that the construct of space has been a very underutilized concept. Ideally, place-based education should adopt local environments, including their social, political, cultural, economic, and natural aspects. Utilizing these components is part of sustainable development. However, most often, place-based education focuses primarily on the natural environment (Ruitenberg 2005). In the context of Millburn and its environmental activist community, displacement as a result of immigration is a big factor that needs to be considered, since much of the community in discussion is of Indian origin. The natural environment in Millburn is actually very unnatural to Millburn's Indian population: the families who migrated from India are used to tropical weather, which makes it harder for them to understand Millburn's local environmental realities.

Ruitenberg (2005) showed that social, political, cultural, economic, and natural contexts need to be married to history, and that people have relevance. The same argument is put forward by Ardoin (2006), who noted that a place is not just biophysical space but also includes socio-cultural, political, psychological, and economic facets. Ardoin (2006) discussed place in the context of environmental education and argued for a more holistic definition of place, to integrate the sense of space with real-world issues of environmental learning, involvement, action, and community-based conservation. 
Indeed, this people-place relationship defines what a community is. Ruitenberg (2005) explained that one's current soil and native soil both influences how one relates to space, dismissing the idea that relocation decontextualizes the individual. Ruitenberg (2005) noted that everyone bears traces of where they lived before. This is particularly true for the Indian residents in Millburn, and is reflected in their way of living and their interaction with nature. True to their roots, many of these residents are in the habit of re-using materials and wasting less food, which they continue to do in Millburn.

Therefore, the pedagogy adopted for environmental education needs to integrate more than just physical space (Ardoin 2006). Since environmental education is inherently holistic, all aspects of space need to be considered. Gruenewald (2003) applied the concept of place-based education to examine the purpose of the social and ecological aspects linked to a place. He also used critical pedagogy to challenge the assumptions, practices, and outcomes linked to dominant cultures in conventional education. Therefore, linking these critical pedagogies with place-based education can be successfully applied to environmental education.

Another element that Gruenewald (2003) highlighted is having empathy as part of a place-based curriculum. He gave the example of loving the earth and conducting exploration that leads to social action; being empathetic about environmental issues is key to a place-based education. As Gruenewald (2003) pointed out, Smith (2002) identified five key elements of an ecologically oriented place-based education: (1) local cultural studies, (2) local nature studies, (3) community issue-investigation and problem-solving, (4) local internships and entrepreneurial opportunities, and (5) induction into community decisionmaking. Learning about a local environmental issue, contacting experts in the local area to get their expertise and perspectives, conducting research, and sharing results for community action were the cornerstones of the Eco Ambassador curriculum. The Eco Ambassador Program also relied on experts in the community who shared their valuable time to discuss student interests and other topics. However, the shared community knowledge and inputs were mainly led by the Indian community in Millburn. Hence, cultural capital formed a large part of the community-based resources that promoted eco-activism and community engagement.

\section{Cultural capital and eco-activism}

The formation of social networks was vital for the Eco Ambassador Program's outreach. Many of the residents who belonged to the "Millburn Climate Action" group hail from India. This itself forms a bond with common cultural capital. Several studies have analyzed the relationship between environment and race/ethnicity. Macias (2016) used General Social Survey data and looked at the racial and ethnic variability in the perceived levels of environmental risk. The study showed that race and ethnicity were strong predictors of perceived threats for climate change and nuclear power generation. It also showed that the environmental values of people of color span over many generations. For example, US-born people of Mexican origin have higher levels of perceived environmental risks than their counterparts. This growing population in the US is more open to environmental action. Macias (2016) noted that race and ethnicity is a determining factor that influences environmental perceptions and possibly actions, among other factors such as socio-economic background, political views, and social networks. Lynch (1993) took a deeper look at US Latino environmental discourse and noted that "environment" is a cultural construct that is shaped by life experiences and thus differs by ethnicity. She suggested that despite 
a great number of Latino mobilizations on environmental events, the environmental discourse is not mainstreamed.

Another study that is worth mentioning is Gilliat-Ray and Bryant's (2011) research, which focuses on the pro-environment attitudes and behaviors of the British Muslim community. Their study found that British Muslims are involved in many projects that promote environmental conservation and sustainable horticulture in the UK. The authors followed this pro-environment behavior in various settings such as mosques and community centers, arguing that these green initiatives by the Muslim community reflect a sense of belonging and ownership of local spaces in the UK. For example, the London-based "Islam Channel" launched a radio show in 2007 called "How Green is your Deen". Deen, or Din, means "religion" in Arabic, and Muslims will often talk about their faith as "the din".

The religious-environmental link is clearly established and is very effective, especially for women. This link helped stop littering issues in some areas. The radio show helped Islamic women form a collective that partnered with local Islamic structures to promote pro-environmental behavior. Gilliat-Ray and Bryant (2011) also cited the Islamic Foundation for Ecology and Environmental Sciences (IFEES), based in Birmingham, which publishes a newsletter (Eco-Islam) that produces guidance and resources for Islamic organizations to develop concepts such as "green" mosques, as well as the Green Guide for Muslims. The authors noted that through its various collective organizing and small green initiatives, the community was able to imbibe a "sense of belonging to, and invest in, local spaces" (p. 295).

Similar to this research on the Muslim community, Mix (2011) investigated the role of social capital in local environmental activism. The author suggested that phone calls and e-mails were important to keep the partners engaged, but face-to-face communication was even more critical. Mix (2011, p. 186) noted that according to an environmental activist, "personal contact" was key to making people understand the issue and also understand varied perspectives. Personal contact is required to build trust. The Millburn case study includes many of these elements, as it is driven by the South-Asian community in New Jersey which relies on many informal networks.

\section{Program description}

The Eco Ambassador Program originated with the Center for Sustainable Development's (CSD) education team at the Earth Institute, Columbia University. The program came about as a means to expand the scope of education for sustainable development (ESD) beyond the core literacy, teacher training, vocational training, and technology skills programming done internationally. Its goal was to make the research and scientific work in the institute accessible and relevant to various sites where the Center's education work was taking place. The education team had been contemplating the use of environmental material in education programming.

The Eco Ambassador Program management team and CSD education leadership includes a Millburn resident, who is also a part of Millburn Climate Action. Through a WhatsApp group, the Millburn community and students started getting involved in some of the programming of the Eco Ambassador Program. The first Eco Ambassador workshop took place in the summer of 2019, when students participated in a 10-week environmental project designed to be completed in a single summer. The program team incorporated Design for Change's Feel-Imagine-Do-Share method into their 10-week summer plan, in 
order to make the projects student-driven and locally relevant, with a framework focusing on compassion and empathy in identifying and tackling environmental issues (Design for Change 2019). This pilot summer program ended with students presenting their research work at the International Conference for Sustainable Development at Columbia University, during UNGA week in September 2019.

After September 2019, the Eco Ambassador Program quickly restarted its programming by popular demand, as many parents and students wanted to participate in the program. The curricular framework had to be widened for a continuous program that was not just project-based but could continuously engage the parents and students. The learning framework became better articulated as the programming and conversations continued and grew, seeking to merge science knowledge with environmental activism, as illustrated in Figure 2.

Through the Eco Ambassador Program website (www.edforsd.org), bi-weekly activities were shared with a WhatsApp group which included around 60 families, $90 \%$ of them of Indian origin. The students got engaged in various research and action projects. Regardless of the topic that the students chose to investigate further, for the environmental component they aimed to apply to at least one of the four main questions in the content framework of the program, as illustrated below in Figure 3.

By design, identifying the issue's everyday implications, action steps, and ways to put their ideas into motion relied on the Eco Ambassadors closely examining and connecting with their local communities and environments. This reinforced the place-based learning emphasis on embodying a wider learning environment. Further, the Eco Ambassador Program lends itself to a Community-based Learning (CBL) Framework. Melaville et al. (2006) outlined six models of CBL: (1) academically based community service, (2) civic education, (3) environment-based education, (4) place-based learning, (5) service learning, and (6) work-based learning. The place-based learning elements were discussed in detail in the literature review. Additionally, in practice the Eco-Ambassador Program involves elements of civic education within eco-activism, to prepare youth to become responsible citizens as they delve into environment-based education, explore the natural world, and form social relationships in the community. As detailed later in this article, the program also took on elements of work-based learning (where young people spend time with adults), especially as the programs adapted to the COVID-19 lockdown and social distancing.

The unifying core characteristics of the six CBL models are articulated as:

- "Meaningful Content. Learning occurs in places and focuses on issues that have meaning for students.

- Voice and Choice. Learning tasks are active and allow students to take an active role in decision making.

- Personal and Public Purpose. Learning goals connect personal achievement to public purpose.

- Assessment and Feedback. Conducting ongoing assessment gives students the opportunity to learn from their successes and failures.

- Resources and Relationships. Community partnerships increase the resources and relationships available for student learning and action" (Melaville et al., p. 9).

Because the program was framed using CBL, these characteristics become apparent in implementation. The ways in which these elements manifest, and how the specific Millburn community embodies these elements, are further described in the Discussion section. 
Figure 2 Eco Ambassador Program framework
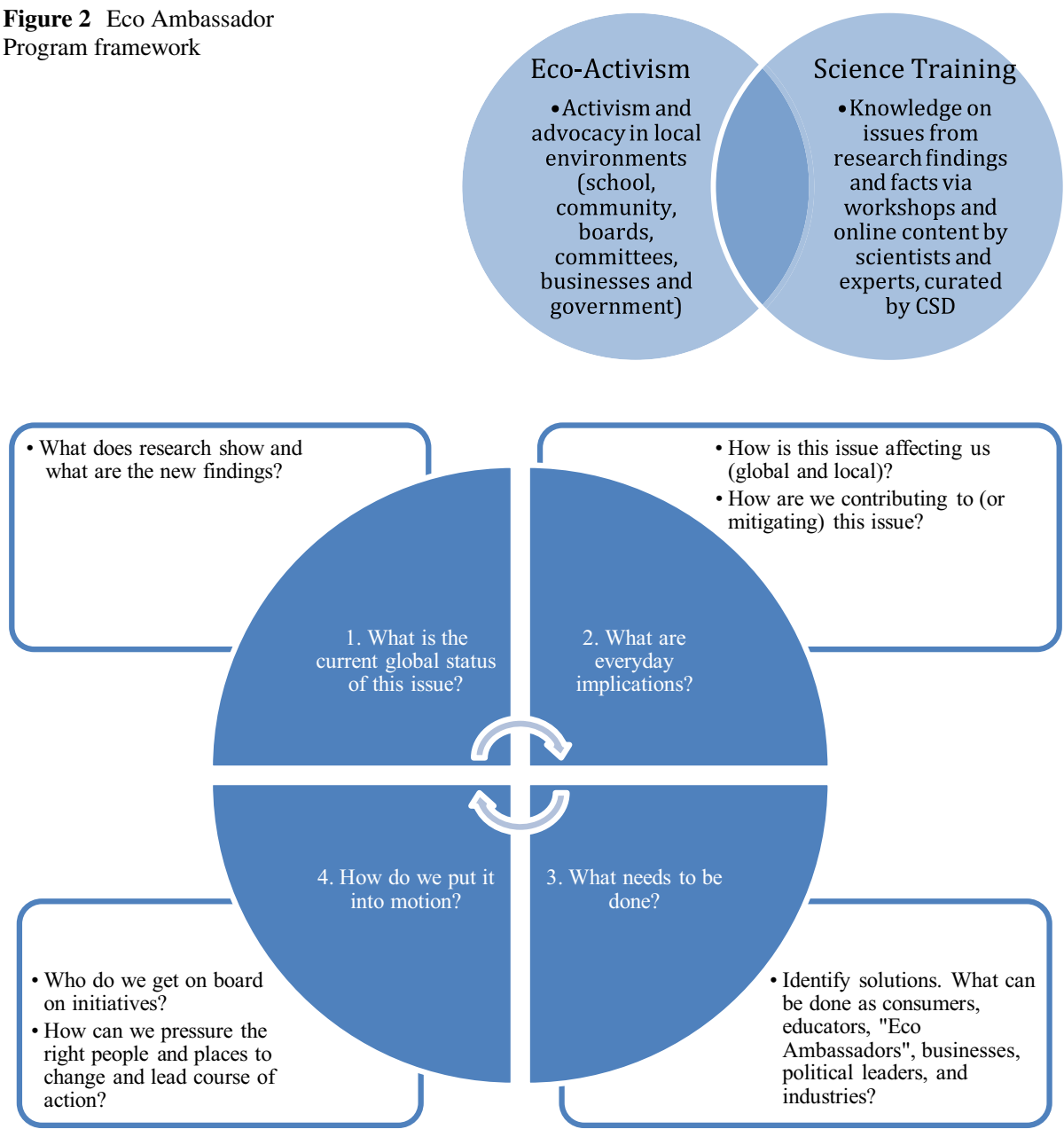

Figure 3 Eco Ambassador Program content framework

Once a month, an in-person meeting was held with a particular focus in mind. They included environment-themed movie screenings, workshop sessions, and social gatherings without any single-use plastic utensils. A bi-monthly Zoom meeting was also scheduled in September 2019, since in-person meetings were hard to coordinate for the Eco Ambassadors living in different towns. The meeting was designed to give space for Eco Ambassadors to share their research and gain feedback from other students. The subsequent meeting time was announced at the end of every meeting. Meanwhile, the Columbia University research team also invited experts and scientists for podcasts and videos, to create a repository of resources so Eco Ambassadors could enact more knowledgeable eco-activism. These resources were then curated on the program website for later use by Eco Ambassadors and their networks.

During the COVID-19 pandemic of 2020, Millburn's school district, like many others in the country, had to close its schools abruptly. All of a sudden, the students had a lot of unstructured time at hand. Some of the Eco Ambassador workshops and in-person events 
planned for March likewise had to be canceled. As an alternative way to connect, the inperson sessions were changed to a series of online workshops. This led to the " 4 pm EDT Daily" series of talks and discussions.

The objective behind the $4 \mathrm{pm}$ Talks were two-fold. First, the main purpose was to discuss one research topic that an Eco Ambassador was investigating, but also to provide feedback on that research. This helped students engage in their topics and also inspire other Eco Ambassadors. Second, the extended social distancing and quarantine made it more important to check on the Eco Ambassadors' psychosocial well-being. The Zoom calls became a means to connect with peer students, who got to see and hear updates which helped to relieve some stress. It was also a mechanism to stay in touch and provide help if needed. Since many of the Eco Ambassadors already knew each other and their families also knew each other, it became an enjoyable social gathering and process along with an educational experience.

The topics included COVID-19 updates from Columbia University public health experts, presentations of school projects such as green roofing, the importance of sunflowers in absorbing harmful chemicals in soil, micro-plastic research, and discussions by experts on the importance of socio-emotional learning. International guests included climate journalists from Mongabay India and Telegraph-Kolkata. Materials recorded prior to the COVID-19 lockdown also helped to shape crowd-sourced blogs written by Eco Ambassadors in Millburn.

During the first four weeks of social distancing and isolation, the program course shifted from monthly in-person sessions to daily conversations at $4 \mathrm{pm}$. Starting in the second week of April, talks began to be converted into workshops. The workshops were spaced out to once every two weeks, with preparatory materials distributed in advance. Each workshop focuses on a different topic, with concrete outcomes in the form of writing, radio production, creative art forms, comics, and sketches, among others. Teamwork is key in all the projects, as well as developing collective skills in research. The sessions also became age- and location-agnostic, with everyone from young students to mothers and teachers joining the sessions to take whatever they could and apply in their lives. The Eco Ambassador Program held more than 25 sessions with 15 to 20 people attending each one.

\section{Discussion and conclusions}

The Eco Ambassador Program has made some noteworthy accomplishments, especially during COVID-19 social distancing and isolation. The solid social networks, already established prior to the outbreak, helped to quickly move involved individuals to adapt and organize online sessions. Informal networks organized via WhatsApp groups made the organization feasible. The collective passion for environmental issues, formed with the inception of the Eco Ambassador Program, served as the basis of the organization. Since many of the participants linked COVID-19 to an environmental crisis, discussions on COVID-19 naturally led to discussions on environmental issues. Their cultural capital and ethnicity also bonded many participants with a common history and a shared experience. For example, food waste and composting were linked to the Indian cultural belief that wasting food is a sin. Therefore, ecological issues were not just place- or topic-specific, but also connected to the lives of people and connected to a common history that this group of Eco Ambassadors shared. The discussion on eliminating plastic, for instance, prompted many participants to share stories of their lives back in India, where single-use plastic is rarely 
used. Therefore, the discussion served to bring back past experiences in a typical Indian household.

Many elements of the critical pedagogy of place were also seen in the discussions. The conversation in many sessions revealed that local schools were not adequately addressing the need for environmental education. Therefore, the students were conducting individual environmental research that was blurring the boundaries between the school and the community. The informal Eco Ambassador discussion platforms over Zoom helped students discuss their ecological interests in great detail and get feedback from their peers. This peer-to-peer encouragement and motivation helped to boost the students' efforts. Their "place", as broadly defined in the literature, served to bring out their common lived experiences in Millburn and among a particular ethic group.

During COVID-19 social isolation, it was very important to have the $4 \mathrm{pm}$ series as a venue to reiterate the importance of washing your hands, practicing social distancing, and keeping the 6-feet distance during essential outings. Participants shared commonly asked questions and answers throughout the COVID-19 developments over the course of weeks and months. The Eco Ambassador workshops and talks also included psychosocial wellbeing components, which included simply taking the time to listen to everyone, smiling often, and sharing ideas on getting over some stress. Given that mental well-being was a key factor during the crisis, one of the sessions was conducted by an art therapist who gave suggestions on keeping mentally active and creatively engaging youth during the isolation period.

Every community has members who specialize in certain areas, either professionally or personally. Since this group of around 65 Indian families had many informal and organized meetings previously, members were familiar with each other's personal and professional expertise. It included home-based composting, food waste reduction, COVID-19 technology initiatives, sustainable gardening, and eco-friendly ways of sustainable living. More general skills, such as writing, poetry, communication, and public speaking, were also applied to environmental issues and topics of personal interest. These topics then transformed into sessions where homebound mothers and kids joined together to share ideas. Sharing the same Indian origins helped to bring out commonality in the kitchens, vegetables people cooked, and lifestyles. Therefore, these shared lived experiences on environmental issues transformed into shared knowledge and ultimately created positive outcomes.

The conversations became a platform in which specific spaces-such as the office, school classroom and home-blended as various skill sets were merged, tapping into personal and professional skills and networks for connection and discussion. This platform also became a space where the information and ideas gained from schools, businesses, jobs, social settings, churches, hobbies, peers, and friends, could all come together in an expanded sense of community. The learning content was further contextualized, because the expertise and information being brought into the group was in part reliant on who was part of the group. The content presented, thus, was very specific, relevant, and personal to those in the group.

Overnight, the COVID-19 outbreak of 2020 brought on unprecedented educational challenges for students, parents, and educators alike. In-person learning programs quickly adapted to become online sessions, necessitated by social distancing measures. The Eco Ambassador Program had already begun to build and expand elements of contextualized learning in its framework by requiring observation of one's personal environment as a starting point, while involving the community in the educational process and eco-activism. However, this gradual process became quickly solidified in a community where a shared sense of identity, ethnic background, and cultural and social connections were deep-rooted. 
This contextualization of contents and place-based learning incorporated multiple elements of space, environment, culture, and identity, enabling a strong learning community even amidst a crisis.

\section{References}

Ardoin, N. M. (2006). Toward an interdisciplinary understanding of place: Lessons for environmental education. Canadian Journal of Environmental Education, 11(1), 112-126.

Design for Change (2019). https://www.dfcworld.com/SITE

Gilliat-Ray, S., \& Bryant, M. (2011). Are British Muslims 'green'? An overview of environmental activism among Muslims in Britain. Journal for the Study of Religion, Nature and Culture, 5(3), 284-306.

Gruenewald, D. (2003). The best of both worlds: A critical pedagogy of place. Educational Researcher, 32(4), 3-12.

Lynch, D. B. (1993). The garden and the sea: US Latino environmental discourses and mainstream environmentalism. Social Problems, 40(1), 108-124.

Macias, T. (2016). Environmental risk perception among race and ethnic groups in the United States. Ethnicities, 16(1), 111-129.

Melaville, A., Berg, A. C., \& Blank, M. J. (2006). Community-based learning: Engaging students for success and citizenship. Partnerships/Community. https://digitalcommons.unomaha.edu/slcepartnership $\mathrm{s} / 40$

Mix, T. L. (2011). Rally the people: building local-environmental justice grassroots coalitions and enhancing social capital. Sociological Inquiry, 81(2), 174-194.

Ruitenberg, C. (2005). Deconstructing the experience of the local: Toward a radical pedagogy of place. In K. Howe (Ed.), Philosophy of education 2005 (pp. 212-220). Urbana, IL: Philosophy of Education Society.

Smith, G. A. (2002). Place-based education: Learning to be where we are. Phi Delta Kappan, 83(8), 584-594.

UNESCO (2020). COVID-19 education disruption and response. https://en.unesco.org/covid19/educationr esponse

United States Census Bureau (2018). Quick Facts Millburn township, Essex County, New Jersey. Population estimates, July 1, 2018. https://www.census.gov/quickfacts/fact/table/millburntownshipessexcoun tynewjersey/PST045218\#PST045218

Publisher's Note Springer Nature remains neutral with regard to jurisdictional claims in published maps and institutional affiliations.

Radhika Iyengar (India, United States) is Director of Education and Research Scholar at the Center for Sustainable Development of Columbia University's Earth Institute. She leads the Education for Sustainable Development initiatives and international development for education as a practitioner, researcher, teacher, and manager. Her research interests focus on conducting evaluations of educational programs and international educational development. She received a distinction from Teachers College, Columbia University on her PhD dissertation, Social capital as a determinant of schooling in rural India: A mixed methods study.

Haein Shin (South Korea, United States) is Education Technical Adviser at the Center for Sustainable Development of Columbia University's Earth Institute. For the past 10 years, she has worked on the implementation, management, monitoring and evaluation and content development of projects in Myanmar, India, Morocco, Saudi Arabia and 10 countries in sub-Saharan Africa. The aim of these projects, mainly focusing on literacy, digital literacy, employment readiness and life skills, and environmental activism, is to build sustainable and resilient communities. She received her Master of Arts in International Educational Development from Teachers College, Columbia University. 